\title{
Laparoscopic partial and total splenectomy in non-trauma patients
}

\author{
Selman Uranüs \\ Department of Surgery, Medical University of Graz, Auenbruggerplatz 29, Graz, Austria
}

\begin{abstract}
Introduction: Developments in equipment and refinements in surgical technique have made minimally invasive surgery possible on parenchymatous organs, including the spleen. Due to the organ's important immunological functions, organ conservation has high priority in spleen surgery, and this must be taken into consideration in laparoscopic surgery.

Materials and Methods: For laparoscopic splenectomy and hemisplenectomy in non-trauma cases, 3 to 4 trocars are used with the patient in semilateral recumbent position. Ultrasonic scissors or Ligasure (Covidien-Medtronic, Inc., Minneapolis, MN, USA) instrument is used to dissect the vessels and mobilize the spleen. The vessels are carefully prepared and, for hemisplenectomy, dissected selectively. For splenectomy, an endostapler with a vascular cartridge is usually used to sever the hilar vessels. For partial resection, the parenchyma is also separated with same instrument. In the present study, 156 patients in a period of 14 years were operated on using this technique: There were 23 resections of the lower pole, 39 of the upper pole, 5 subtotal resections, and 89 splenectomies.

Results: Laparoscopic splenectomy or hemisplenectomy was successfully completed in 152 of 156 patients. Four patients had to be converted to open technique due to intraoperative bleeding. No patient required reoperation and hospital mortality was 0 . In every case of diagnostic partial resection of the spleen, it was possible to establish firm diagnosis.

Conclusion: Laparoscopic operation on spleen with long axis of up to $24 \mathrm{~cm}$ is expedient and practicable. For spleen of normal or slightly enlarged size, laparoscopy can even be seen as the standard procedure for splenectomy. Patients with hematological disorders have greater surgical risk due to the comorbidity; it is they who receive the greatest benefit from this approach.
\end{abstract}

Keywords: Hemisplenectomy; laparoscopy; spleen; splenectomy; splenic partial resection.

\section{Introduction}

Up to 30 years ago, it was thought that the spleen, called the "organum plenum mysterii" by Galen, could be removed without any qualms. A follow-up study by Seifert covering 150 patients who had undergone posttraumatic splenectomy revealed that $2.6 \%$ of the patients had succumbed to severe infections, ${ }^{[1]}$ and $20 \%$ suffered from frequent infections. In a retrospective analysis of 2796 patients, Singer found septic infections in $119(4.25 \%){ }^{[2]}$ 
Seventy-one patients $(2.52 \%$ of the total patients and $60 \%$ of those with infections) died of sepsis. Sepsis causes death 200 times more frequently in splenectomized patients than in the general population. According to Singer, the incidence of sepsis mortality is $0.01 \%$ in the general population, ${ }^{[2]}$ while it is $0.58 \%$ following posttraumatic splenectomy, $0.85 \%$ following incidental splenectomy and even higher following splenectomy for hematological reasons (thalassemia 11\%, hemolytic anemia 2.9\%, portal hypertension 5.9\%). The most common pathogens are Pneumococcus, Meningococcus, Haemophilus influenzae, Escherichia coli, Stapylococcus, Neisseria meningitis and Salmonella spp.

The primary immunological task of the spleen is to filter virulent pathogens and antigens. As the spleen has no afferent lymph vessels, it is mainly responsible for defense against hematogenic infections. This is accomplished in two ways, corresponding to the histological structure of the spleen: on the one hand, with the white pulp, which as the central lymphoreticular organ harbors most of the T-lymphocytes, and on the other, with the red pulp, with most of the B-lymphocytes. Preservation of immunological function requires $25 \%$ of the initial weight of normal spleen for the patient's age, whereby adequate arterial blood supply is an important prerequisite. ${ }^{[3]}$

The first documented splenectomy was performed in Palermo by Zaccarello of Palo. In 1991, only four years after the beginning of the laparoscopic era, Delaitre ${ }^{[4]}$ reported the first laparoscopic splenectomy. With rapid developments in instruments and imaging systems, laparoscopy gained popularity for spleen surgery, ${ }^{[5,6]}$ and today, laparoscopic splenectomy is nothing unusual. In some indications, laparoscopy is on its way to becoming standard, though splenectomy in trauma cases remains within the domain of conventional open surgery. ${ }^{[7]}$

Shortly after the first publication of a laparoscopic splenectomy, experimental and the clinical partial resections of the spleen were reported. ${ }^{[8,9]}$ This procedure would be indicated fairly often, though total resection is usually preferred out of fear of bleeding, so that hemisplenectomy was considered to be counterproductive. Laparoscopic spleen surgery is basically elective and falls into two groups: complete removal of the entire spleen, and partial removal of the spleen.

\section{Materials and Methods}

\section{Laparoscopic Splenectomy}

Spleens with a craniocaudal axis of maximally $24 \mathrm{~cm}$ measured sonographically are most suitable for laparoscopy. Larger spleens can be removed with a hand port for laparoscopic assistance. These spleens, however, require such unfavorable trocar placements and specimen retrieval can necessitate such large incisions that laparoscopy does not make sense.

\section{Indications (Table 1):}

Splenectomy in non-trauma cases basically has one or more of these aims:

a. Prevention of anemia through increased elimination of corpuscular elements of the blood in the pulp due to one of the three congenital erythrocyte diseases: disease of the erythrocyte membrane; hemoglobinopathies; enzymatic defects,

b. Treatment of splenomegaly and hypersplenism,

c. Diagnosis and staging of lymphomatic disease

Preoperative preparation: As with open surgery, two weeks before the planned spleen surgery, the patient should receive a Pneumococcus immunization. If this is not done beforehand, it should be done 1-2 weeks after surgery. The patient should be free of infection at the time of immunization. This procedure applies to adults as well as pediatric and juvenile patients. Prophylactic long-term administration of antibiotics has so far not proven to be effective for preventing infections in asplenic persons. When an infection occurs, antibiotics should be given early and more generously than usual. Patients should be informed about their susceptibility to infections.

Position on the operating table: For both total and partial resections of the spleen, the patient is placed in the right semilaterial position with the left arm fixed over the head. The patient's back should be at an angle of $45^{\circ}$ to $60^{\circ}$ to the table (Figure 1). In this position, the abdominal organs are shifted away from the spleen while the spleen remains fixed by its ligaments in the subphrenic space. This allows better overall view and safe access to the splenic hilus.

The supine position, however, is better for seeking accessory spleens, so that when the operation on the spleen is over, the patient is brought into that position by turning 
Table 1. General indications for splenectomy

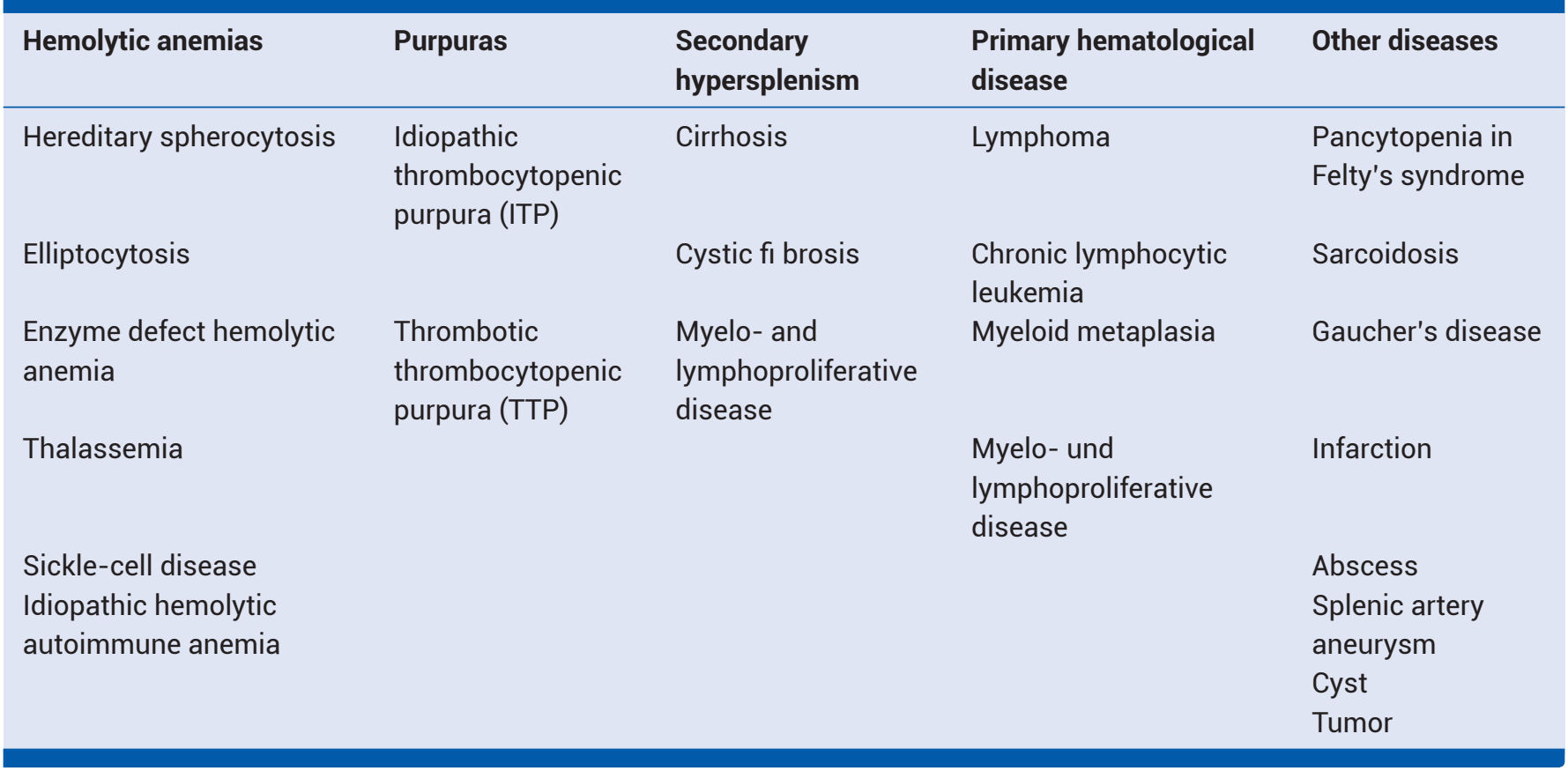

the operating table.

Positions of the trocars: In general, 3 and rarely 4 trocars are used for operations on the spleen. The first is a $10 \mathrm{~mm}$ trocar for the optic; depending on the size of the spleen it is inserted in the midline, supra- or infra-umbilically. The working trocars are placed on the epigastrium and in the left medioclavicular line; usually more are not needed but when necessary, a fourth trocar for a retractor can be located in the left anterior axillary line or subxyphoidally. The trocar for the insertion of the endostapler should have a diameter of $12 \mathrm{~mm} ; 5 \mathrm{~mm}$ suffice for the other working trocar (Figure 2).

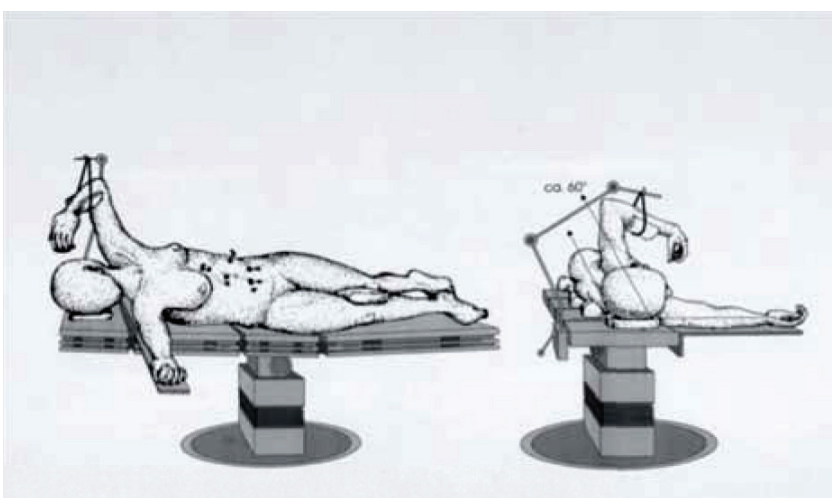

Figure 1. Schematic presentation of the position of the patient on the operating table.

\section{Steps for the Operation}

Mobilization: After a brief inspection of the abdomen, the splenic region is examined for accessory spleens which, depending on their position are removed either immediately or after removal of the spleen. Dissection of the spleen is begun ventrally with transection of the connections to the omentum from caudal to cranial. The dissection should be made with slight tension on the omentum as close as possible to the spleen but without injury to the splenic capsule. The short gastric vessels are severed at this stage. The dissection is facilitated with the use of ultrasonic scissors (Ultracision ${ }^{\circledR}$, Ethicon; Ultrasonix ${ }^{\circledR}$, Covidien) or a vascular sealing system (LigaSure ${ }^{\circledR}$, Covid-

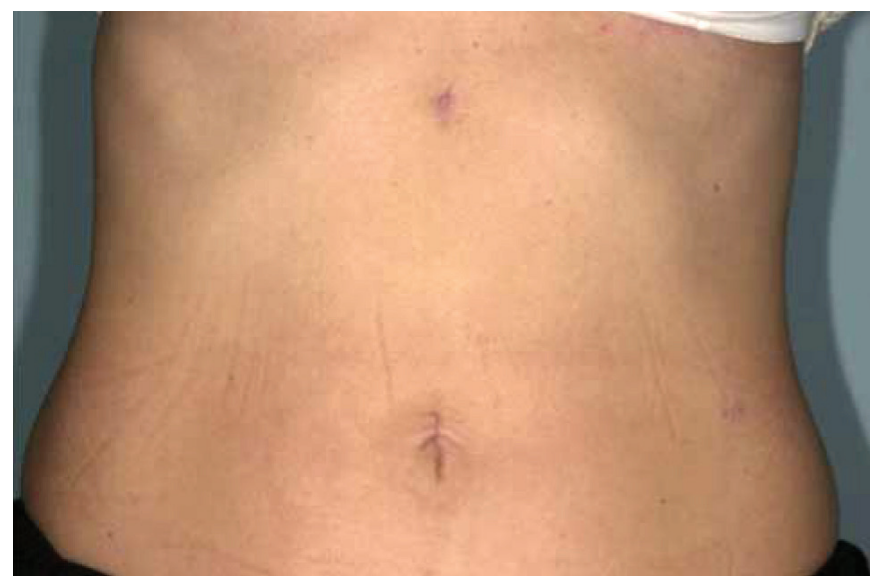

Figure 2. Points of insertion of trocars a few days after splenectomy or subtotal hemisplenectomy. 


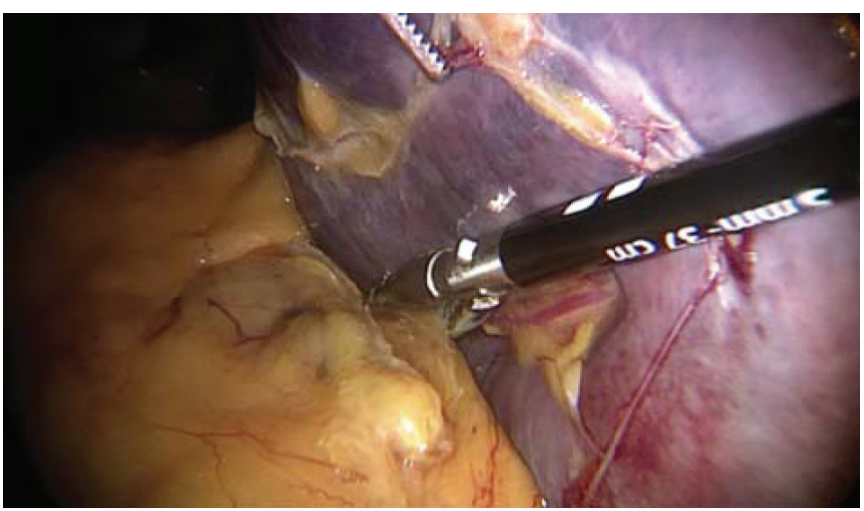

Figure 3. Dissection of the hilar vessels with the $5 \mathrm{~mm}$ Ligasure $^{\circledR}$ instrument.

ien) (Figure 3). Mobilization so can proceed safely, faster and without application of hemoclips.

When all of the omental connections on the medial surface have been severed and the main vessels are visible, dorsolateral mobilization follows with severing of the peritoneal fold, also from caudal to cranial. Blood supply to the tail of the pancreas should be preserved via the last segment of the splenic vessels, or the gastroepiploic vessel.

Dissection of the hilar vessels: For a safe, bloodless separation of the hilar vessels, attention should first be given to the lower polar vessels. They can be cut with ultrasonic scissors or the Ligasure ${ }^{\circledR}$ instrument, if they are not too highly calibrated. Sometimes the lower polar vessels give off a number of branches; these should be cut stepwise and carefully. Only then can the hilar vessels be dissected. Dissection of the hilus is safest with an endostapler introduced through the $12 \mathrm{~mm}$ trocar on the medioventricular line. With splenomegaly, there can be very dilated and ramified hilar vessels that run between the packets of lymph nodes; these are best severed with an endostapler loaded with a $60 \mathrm{~mm}$ vascular cartridge. Depending on the distribution and width of the hilar vessels, they can be dissected stepwise using two or more cartridges. Endostapler resection is faster, safer and more effective than resection with hemoclips.

Sealing and tamponading the wound surface: When all the connections have been severed, the spleen is temporarily placed on the right upper abdomen. The splenic fossa is rinsed and any bleeds are attended to.

Use of hemostyptic substances like fibrin adhesive and collagen fleece provides additional safety for patients with increased tendency to bleed, as with thrombocytope- nias, coagulopathies or liver cirrhosis. Both heterologous (Tisseel ${ }^{\circledR}$, Baxter, Germany) and homologous fibrin adhesives (Vivostat ${ }^{\circledR}$, Vivolution A/S, Denmark) have proved to be suitable. The fibrin adhesive can be sprayed deep into the wound, assuring optimal sealing of the wound surface. Combined use of fibrin adhesive with collagen fleece (TissuVlies ${ }^{\circledR}$, Baxter Germany) that is applied to the stumps of the blood vessels and cut edge of the spleen and fixed with fibrin adhesive provides better prevention of afterbleeding. Slightly active bleeding from the parenchyma can be stopped by using Hemopatch ${ }^{\circledR}$ (Baxter, Germany). Drainage of the left subphrenic space is reserved for special cases.

Retrieving the specimen: The spleen is always removed from the abdomen in a sufficiently large, waterproof retrieval bag. Larger bags that require an $18 \mathrm{~mm}$ trocar can be inserted through the umbilical incision after the trocar has been removed; this opening can be enlarged as necessary for removal of the specimen. With some benign indications such as idiopathic thrombocytopenic purpura (ITP) or spherocytosis, detailed histology is not necessary. These spleens can be morcellated in the retrieval bag and removed through much smaller openings. For other indications, it can be advantageous to morcellate the spleen into larger pieces, as this will not compromise histological examination. It is important to avoid accidental splenosis by disseminating bits of parenchyma in the abdomen.

Postoperative management: It is generally advisable to use a gastric tube as it will decompress the stomach and provide a better view. When the patient is fully awake, it can be removed and liquids can be given by mouth. Progressive oral feeding usually begins on the first postoperative day. One perioperative dose of a broad-spectrum antibiotic suffices for prophylaxis. A transfusion of thrombocytes in ITP patients should, if necessary, only be given after dissection of the main vessels earliest. Postoperative leuco- and thrombocytosis should be borne in mind as they can develop with splenectomy and loss of the organ's reservoir function. Thrombosis prophylaxis should follow current guidelines.

\section{Partial Splenectomy}

\section{Indications (Table 2):}

A laparoscopic splenectomy is usually performed for a benign lesion such as a cyst or hamartoma. Beyond a size of 2 to $3 \mathrm{~cm}$, these lesions can cause symptoms of varying severity. The symptoms depend on the size of the lesion 
Table 2. Indications for partial splenic resection

\begin{tabular}{|c|c|c|}
\hline Diagnostic & Therapeutic & Injury \\
\hline $\begin{array}{l}\text { Intralienal tumors } \\
\text { of unclear dignity }\end{array}$ & $\begin{array}{l}\text { Splenic cyst } \\
\text { (non-parasitic) }\end{array}$ & $\begin{array}{l}\text { Non-traumatic } \\
\text { accidental } \\
\text { laceration }\end{array}$ \\
\hline $\begin{array}{l}\text { Splenomegaly of } \\
\text { unclear origin }\end{array}$ & $\begin{array}{l}\text { Benign tumor } \\
\text { (hamartoma, } \\
\text { fibroma, } \\
\text { pulpoma) } \\
\text { Metastasis } \\
\text { (gynecologic) } \\
\text { Infarct } \\
\text { Intrasplenic } \\
\text { pancreatic } \\
\text { cyst }\end{array}$ & \\
\hline
\end{tabular}

and range from diffuse upper abdominal pain to dyspnea. Large cysts may compress other organs, giving rise to feelings of fullness and disturbances in largeintestinal passage. Cysts that are larger than $5 \mathrm{~cm}$ and located on the edge of the organ are much more likely to rupture with even mild trauma. In two of our own patients, we saw bleeding into a cyst that caused symptoms similar to a heart attack, whereupon they were admitted to the cardiology service. When a lymphoma is suspected, it can be easier and safer to perform a diagnostic hemisplenectomy than to obtain a representative biopsy from retroperitoneal lymph nodes.

It should be noted that with both laparoscopic and open surgery, there is no need to remove the entire spleen when a partial splenectomy will achieve the stated therapeutic goal.

Preoperative preparation: This is the same as for laparoscopic splenectomy. Patients should also receive a Pneumococcus immunization and be briefed accordingly.

Position on the operating table: As for laparoscopic splenectomy, the patient is placed in the right semilateral position (Figure 1). The number and positions of the trocars are the same. With partial resections, the transection of the splenic parenchyma is from medial via a $12 \mathrm{~mm}$ trocar on the epigastrium.

\section{Steps for the Operation}

The first step of a partial resection is also mobilization, but unlike open partial resection, with laparoscopic tech- nique only the part of the spleen is mobilized that later will be removed. When the lower half of the spleen is to be removed, first the omental connections and the branches of the gastroepiploic artery are severed, preferably with ultrasonic scissors or a Ligasure ${ }^{\circledR}$ instrument.

For resection of the upper half of the spleen, mobilization begins on the visceral facies at the height of the planned resection line. First, the omental connections and the short gastric vessels are severed, followed by dorsal mobilization of this segment. Then the vessels supplying this area are severed, preferably with the Ligasure ${ }^{\circledR}$ instrument.

With few exceptions, the parenchyma is transected with an endostapler loaded with a $60 \mathrm{~mm}$ blue cartridge. The parenchyma is compressed with a long atraumatic grasping forceps along the planned demarcation line that is

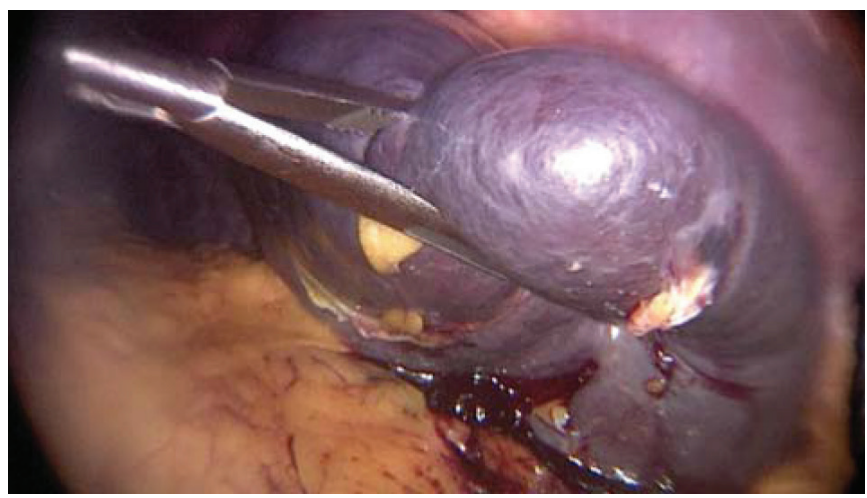

Figure 4. The parenchyma is compressed with a long atraumatic grasping forceps along the demarcation line.

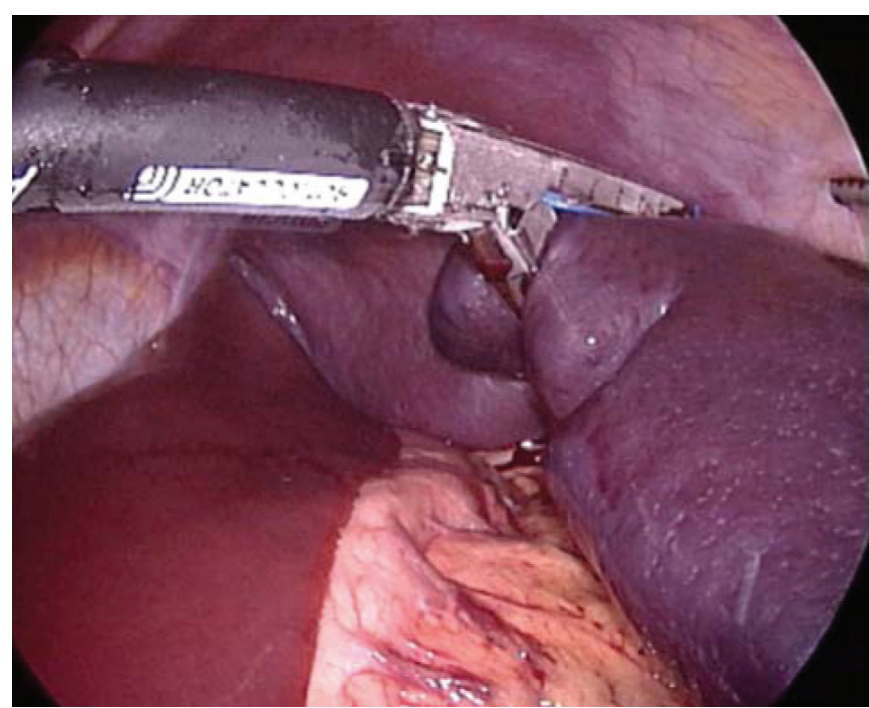

Figure 5. Stepwise parenchyma resection with the endostapler on the demarcation line in a pediatric spherocytosis patient with splenomegaly. 
Table 3. Patients with laparoscopic splenic procedures $n=156$ (1998-2012)

\begin{tabular}{|c|c|c|c|c|c|}
\hline Procedure & No. of patients & ITP & Chronic anemia & Malignant lymphoma & Metastasis \\
\hline Splenectomy & 89 & 57 & 15 & 16 & 1 \\
\hline Procedure & No. of patients & Cysts & Hamartomas & Metastasis & \\
\hline Partial splenectomy & 67 & 56 & 9 & 2 & \\
\hline
\end{tabular}

easily seen due to the previous vascular dissection (Figure 4). Only when the parenchyma is sufficiently compressed is the endostapler introduced through the epigastric 12 $\mathrm{mm}$ trocar and the resection done stepwise (Figure 5).

With extensive lesions that extend into the neighboring segment that is not to be resected, the cystic tissue is peeled out, taking care not to leave the cystic wall in place.

The cut edge of the remaining spleen is, as with laparoscopic splenectomy, sealed with fibrin adhesive and tamponaded with collagen fleece to prevent afterbleeding. With both fibrin adhesive and collagen fleece, the spleen quickly adheres to its surroundings, reducing the chances of torsion or kinks in the venous area.

As with total splenectomy, the specimen is retrieved in a sufficiently large, waterproof retrieval bag. In most cases, the specimen can be morcellated and then removed through a relatively small incision.

Postoperative management is as for splenectomy.

\section{Results}

From 1998 to 2012, 89 laparoscopic splenectomies and 67 partial splenectomies were performed (Table 3).

\section{Laparoscopic Splenectomy}

The criteria for laparoscopic surgery were besides fitness for surgery a long axis of the spleen measured sonographically that did not exceed $24 \mathrm{~cm}$. According to this selection criterion, all the spleens extirpated laparoscopically did not exceed $1000 \mathrm{~g}$ in weight. There were 57 ITP patients, 15 with chronic anemia, 16 with a malignant lymphoma and one with a solitary splenic metastasis after ovarian carcinoma. Two (2.2\%) patients required conversion to open technique. One of these was a lymphoma patient with venous hilar bleeding and the other had ITP. The lowest thrombocyte count among the non-converted purpura patients was 9000. No mortalities among laparoscopically splenectomized patients were related to the surgery.

\section{Laparoscopic Partial Splenectomy}

Sixty-seven patients aged 13 to 72 years underwent a partial splenectomy, 23 of the lower and 39 of the upper pole. The remaining 5 patients underwent subtotal resection, 4 for extensive cysts and a 14-year old girl with spherocytosis for reduction of the spleen. Fifty-six patients underwent surgery for symptomatic splenic cysts, 5 of them with recurrences. All of the latter had primarily undergone de-roofing. Among the patients with recurrent cysts were a 13-year old girl who had had two laparoscopic surgeries and an 18-year female patient who had had one open surgery. In all the patients with recurrences, they developed within a few months and caused severe complaints. Nine patients were operated due to hamartomas. Two patients had a partial splenic resection for splenic metastases from an ovarian carcinoma; both were otherwise tumor free following radical surgery and chemotherapy.

Two patients had to be converted to open technique. Lethality was 0 and only two patients required blood transfusions: the 14-year old girl with spherocytosis received two units of concentrated erythrocytes and the 72-year old man with a $7 \mathrm{~cm}$ diameter hamartoma received three units.

\section{Discussion}

The tactics for splenic surgery have changed greatly since the discovery in the second half of the $20^{\text {th }}$ century of the organ's important immunological functions. Previously, the only option had been total removal of the entire organ, while in the last 30 years, the number of organ-preserving measures has constantly increased. ${ }^{[10-12]}$

This trend should continue unchanged in the laparoscopic era, though there are major differences in technique between open and laparoscopic surgery, especially with 
regard to partial resection. In open surgery, complete mobilization of the spleen is an important prerequisite for successful partial resection, while with laparoscopic technique, only the portion of the spleen is mobilized that is to be resected. The spleen remnant remains fixed in its fossa thanks to the remaining ligamentous connections, facilitating the application of the stapler. ${ }^{[13]}$

A further positive aspect of the reduced extent of mobilization is the reduction of the wound surface, which in open surgery is much larger when the spleen and the tail of the pancreas are lifted onto the abdominal wall. The manipulation of the tail of the pancreas and the larger wound to the retroperitoneum are the risk factors for afterbleeding and lesions on the tail of the pancreas.

The possibility of minimally invasive splenic surgery has changed the thinking of hematooncologists in recent years. The indications for diagnostic and therapeutic splenic surgery have expanded because laparoscopic procedures can be performed on these patients, who in any case have higher risk and mortality, with fewer complications and less stress for the patients. Laparoscopy so has come to be standard procedure for normal and moderately enlarged spleens of up to $24 \mathrm{~cm}$. Larger spleens require unfavorable and atypical trocar placements, and laparoscopy is often assisted with a hand port. Even if the spleen is morcel-lated for retrieval, larger incisions are needed so that many important advantages of minimally invasive technique are lost in these cases. ${ }^{[14]}$

We find that three points are especially important for a successful operation on the spleen. These are: position of the patient; trocar positions; use of modern coagulation and cutting instruments.

With the patient in the normal supine position, the spleen lies far back in its fossa; it is usually covered by the greater curvature of the stomach and the greater omentum and not immediately visible. Only in the right semilateral position do the neighboring organs slide away from the spleen, while the spleen itself remains close to the diaphragm, suspended from its ligamentous connections. In this position, the organ can easily be approached from the hilus as well as from dorsal and lateral. A moderately enlarged spleen with a maximum length of $24 \mathrm{~cm}$ reaches the level of the navel, so that depending on the position of the lower pole, the first trocar can be introduced on the midline on the super- or infraumbilical fold. The second trocar is located on the medioclavicular line to the left of the umbilicus and at the level of the latter or slightly below it. As the endostapler will be inserted through this trocar for splenectomy, it should have a diameter of $12 \mathrm{~mm}$. The third trocar measures $5 \mathrm{~mm}$ and is installed on the epigastrium at the midpoint between navel and xyphoid. For partial resections, the endostapler is inserted through the epigastic trocar, which accordingly should have a diameter of $12 \mathrm{~mm}$.

Ultrasonic scissors or the Ligasure ${ }^{\circledR}$ instrument makes dissection easier and safer and avoids the use of hemoclips when tissues and blood vessels are cut. With the Ligasure ${ }^{\circledast}$, vessels of up to $7 \mathrm{~mm}$ can be reliably sealed and severed, so that the lower and upper polar vessels can be dissected without a stapler. Without constant instrument changes, operations are faster and bloodfree. ${ }^{[13]}$

It should be mentioned that when it is a matter of trauma, both splenectomies and organ-preserving surgeries remain in the domain of open surgery. Technically, a laparoscopic mesh splenorrhaphy is feasible, but that procedure is only indicated for heavily bleeding spleens with grade 3 to 4 injuries; logically, it is not indicated for a spleen that is not bleeding at the time of laparoscopy. A basic prerequisite for laparoscopy for abdominal trauma is hemodynamic stability in the absence of any signs of active bleeding, but patients with a splenic injury who are hemodynamically stable should not undergo surgery anyway. ${ }^{[15-17]}$ Splenorrhaphy for spleens that are not actively bleeding is actually contraindicated because to apply the mesh, the entire spleen must be mobilized and the short gastric vessels severed, putting the trauma patient at unnecessary further risk.

To summarize: thanks to increasing experience with laparoscopic surgery and constantly improving instruments, both splenectomies and partial splenectomies can be performed quickly and safely with this technique. It is no longer necessary to remove the entire organ for fear of bleeding. If the appropriate guidelines are followed, today it is even possible to perform laparoscopic partial resections on enlarged spleens.

\section{Disclosures}

Ethichs Committee Approval: The study was approved by the Local Ethics Committee.

Peer-review: Externally peer-reviewed.

Conflict of Interest: None declared. 


\section{References}

1. Seifert J, Brieler S, Reese F, Hamelmann H. Risk of infection following splenectomy. Langenbecks Arch Chir 1986;369:269-72. [CrossRef]

2. Singer, D.B. Postsplenectomy sepsis. in: H.S. Rosenberg, editor. Perspectives in pediatric pathology. 1st ed. Chicago: RP Bolande Year Book Medical Publishers; 1973: p. 295-307.

3. Uranüs S. Physiology of splenic function. In: Uranüs $S$, editor. Current Spleen Surgery. München Bern Wien NewYork: W Zuckschwerdt Verlag; 1995: p. 11-3.

4. Delaitre B, Maignien B. Splenectomy by the laparoscopic approach. Report of a case. Presse Med 1991;20:2263.

5. Carroll BJ, Phillips EH, Semel CJ, Fallas M, Morgenstern L. Laparoscopic splenectomy. Surg Endosc 1992;6:183-5.

6. Targarona EM, Espert JJ, Balagué C, Piulachs J, Artigas V, Trias M. Splenomegaly should not be considered a contraindication for laparoscopic splenectomy. Ann Surg 1998;228:35-9.

7. Uranüs S, Fingerhut A, Kronberger L, Pfeifer J, Mischinger HJ. Splenic trauma. Acta Chir Austriaca European Surg 1999;31:75-9. [CrossRef]

8. Uranüs S, Pfeifer J, Schauer C, Kronberger L Jr, Rabl H, Ranftl
G, et al. Laparoscopic partial splenic resection. Surgical Laparoscopy \& Endoscopy 1995;5:133-6.

9. Uranüs S, Peng Z, Kronberger L, Pfeifer J, Salehi B, Rabl H. Laparoskopische milzteilresektion. Acta Chir Austriaca 1997;29:74-5.

10. McClusky DA 3rd, Skandalakis LJ, Colborn GL, Skandalakis JE. Tribute to a triad: history of splenic anatomy, physiology, and surgery-part 2. World J Surg 1999;23:514-26. [CrossRef]

11. Uranüs S, Pfeifer J. Nonoperative treatment of blunt splenic injury. World J Surg 2001;25:1405-7. [CrossRef]

12. Peitzman AB, Ford HR, Harbrecht BG, Potoka DA, Townsend RN. Injury to the spleen. Curr Probl Surg 2001;38:932-1008.

13. Uranues S, Alimoglu O. Laparoscopic surgery of the spleen. Surg Clin North Am 2005;85:75-90. [CrossRef]

14. Uranues S, Grossman D, Ludwig L, Bergamaschi R. Laparoscopic partial splenectomy. Surg Endosc 2007;21:57-60.

15. Ivatury RR. Laparoscopy and thoracoscopy in penetrating thoracoabdominal injuries. Eur Surg 2005;37:19-27. [CrossRef]

16. Alimoglu O. Laparoscopy in penetrating abdominal trauma. Eur Surg 2005;37:28-32. [CrossRef]

17. Uranüs S. Laparoscopy in blunt abdominal trauma. Eur Surg 2005; 37:33-6. [CrossRef] 